\title{
Ovarian Endometrioid Adenocarcinoma with Squamous Differentiation
}

National Cancer Institute

\section{Source}

National Cancer Institute. Ovarian Endometrioid Adenocarcinoma with Squamous

Differentiation. NCI Thesaurus. Code C40061.

An endometrioid adenocarcinoma that arises from the ovary and exhibits squamous differentiation. The squamous cell component often has a cytologically benign appearance. 